\title{
Contrasting development of lysigenous aerenchyma in two rice genotypes under phosphorus deficiency
}

Vincent Pujol[10 and Matthias Wissuwa*

\begin{abstract}
Objectives: Phosphorus (P) deficiency is a major limitation to plant growth. Under several abiotic stresses, including $P$ deficiency, upland cereal crops, such as maize, are well known to develop lysigenous aerenchyma, a root tissue containing gas spaces. Contrary to upland species, rice develops aerenchyma constitutively. Nevertheless, aerenchyma in rice is also enhanced by several abiotic stresses, including P deficiency. However, studies are limited and genotypic differences are not clear.

Results: The formation of inducible aerenchyma in response to $P$ deficiency was evaluated in two rice genotypes, DJ123 and Nerica4. Whole root porosity increased for both genotypes in low P conditions, but was more pronounced in DJ123. Direct aerenchyma measurements, at 20 and $30 \mathrm{~mm}$ from the seminal root tip, revealed that aerenchyma in low P conditions was only enhanced in DJ123. These results confirm that P deficiency in rice induces the formation of aerenchyma, and further show that genotypic differences exist. Interestingly, DJ123 is considered tolerant to P deficiency, whereas Nerica4 is sensitive, pointing towards a potential role of aerenchyma in tolerance to $P$ deficiency.
\end{abstract}

Keywords: Lysigenous aerenchyma, Phosphorus deficiency, Rice, Root porosity, Phosphorus use efficiency

\section{Introduction}

Phosphorus (P) deficiency is a major limitation to plant growth and is typically counterbalanced through the heavy application of mineral fertilizers, which is inefficient, polluting and expensive $[1,2]$. Improving plants' ability to take up and use P efficiently is therefore essential for the development of sustainable farming and to ensure global food security. In this regard, lysigenous aerenchyma is seen as a positive factor, as it allows the plant to reduce cell cost maintenance as well as to remobilize nutrients, thereby enabling growth $[3,4]$.

Aerenchyma is a tissue containing enlarged gas spaces, which allow the diffusion of gases, notably, oxygen from shoots to roots, and $\mathrm{CO}_{2}$ and ethylene from roots to shoots [5]. In cereal crops such as rice, maize, barley and wheat, lysigenous aerenchyma is formed in the root cortex following the death of cortical cells, via programmed

\footnotetext{
*Correspondence: wissuwa@affrc.go.jp

Crop, Livestock and Environment Division, Japan International Research Center for Agricultural Sciences (JIRCAS), Tsukuba, Ibaraki, Japan
}

cell death [5]. In dryland plants, lysigenous aerenchyma is known to be induced by waterlogging and nutrient deficiency [5-7]. In contrast, rice (Oryza sativa L.) forms lysigenous aerenchyma constitutively, without experiencing any stress [8]. Nevertheless, aerenchyma is also enhanced by several abiotic stresses [9-11], including $P$ deficiency [12]. This was mainly observed via the increase in root porosity, which indirectly reflects the formation of aerenchyma [13-15]. To date, genotypic differences are not clear and the role of aerenchyma in tolerance to $\mathrm{P}$ deficiency has not been addressed.

In this study, the formation of inducible lysigenous aerenchyma in rice, in response to low $\mathrm{P}$ conditions, was evaluated in detail to complement previous studies. Two rice genotypes, DJ123 (DJ) and Nerica4 (N4), were used to detect potential genotypic differences. In addition, these genotypes contrast in their tolerance to $P$ deficiency; N4 is sensitive while DJ is tolerant $[16,17]$. Seedlings were grown under high and low $\mathrm{P}$ conditions and whole root porosity as well as the proportion of aerenchyma near the seminal root tip were evaluated. 


\section{Main text \\ Methods \\ Plant growth}

Two rice varieties were used: DJ123 (DJ-O. sativa ssp. aus) and Nerica4 (N4-O. sativa $\times$ O. glaberrima). Seeds of DJ123 were sourced from the IRRI gene bank (IRGC117711) and seeds of Nerica4 were held at JIRCAS after an original import from Africa in 2010. Seeds were incubated at $50{ }^{\circ} \mathrm{C}$ for 2 days to break dormancy, then surface-sterilized $\left(0.5 \% \mathrm{NaOCl}+0.15 \mathrm{M} \mathrm{KH}_{2} \mathrm{PO}_{4}\right)$ and germinated in the dark at $28{ }^{\circ} \mathrm{C}$ for 3 days. Uniform germinated seeds were transferred onto floating mesh in 20 $\mathrm{L}$ deionized water in glasshouse (light $>12 \mathrm{~h}, 26-30{ }^{\circ} \mathrm{C}$, humidity 50-90\%). Genotypes were grown together in two (microscopy 1) or three (porosity and microscopy 2) containers per $P$ treatment. FeEDTA $(12 \mu \mathrm{M})$ and $\mathrm{CaCl}_{2}(100 \mu \mathrm{M})$ were added after 2 days. From 10 days after germination, solution was replaced on a weekly basis with modified Yoshida solution [18] at 1/3, 1/2 and full strength. Full strength Yoshida solution contained $\mathrm{NH}_{4} \mathrm{NO}_{3}(\mathrm{~N}: 2.86 \mathrm{mM}), \mathrm{K}_{2} \mathrm{SO}_{4}(\mathrm{~K}: 1.02 \mathrm{mM})$, $\mathrm{CaCl}_{2} \cdot 2 \mathrm{H}_{2} \mathrm{O}(\mathrm{Ca}: 1 \mathrm{mM}), \mathrm{MgSO}_{4} \cdot 7 \mathrm{H}_{2} \mathrm{O}(\mathrm{Mg}: 1.65 \mathrm{mM})$, $\mathrm{MnCl}_{2} \cdot 4 \mathrm{H}_{2} \mathrm{O} \quad(\mathrm{Mn}: \quad 9.1 \mu \mathrm{M}), \quad\left(\mathrm{NH}_{4}\right)_{6} \cdot \mathrm{Mo}_{7} \mathrm{O}_{24} \cdot 4 \mathrm{H}_{2} \mathrm{O}$ (Mo: $0.52 \mu \mathrm{M}$ ), $\mathrm{H}_{3} \mathrm{BO}_{3}$ (B: $\left.18.5 \mu \mathrm{M}\right), \mathrm{ZnSO}_{4} \cdot 7 \mathrm{H}_{2} \mathrm{O}$ (Zn: $0.15 \mu \mathrm{M}), \mathrm{CuSO}_{4} \cdot 5 \mathrm{H}_{2} \mathrm{O}(\mathrm{Cu}: 0.16 \mu \mathrm{M})$ and EDTA iron(III) sodium salt (Fe: $35.81 \mu \mathrm{M})$. P treatment $\left(\mathrm{NaH}_{2} \mathrm{PO}_{4} \cdot 2 \mathrm{H}_{2} \mathrm{O}\right)$ started 10 days after germination, in quantities corresponding to 100 (high) and 1 (low) $\mu \mathrm{M}$ $\mathrm{P}$ in full strength Yoshida solution. $\mathrm{pH}$ was regularly adjusted to approx. 5.7 and the solution was constantly aerated by gentle bubbling.

\section{Root porosity}

At 17 and 18 days post-treatment (DPT), six replicates (three per day), corresponding to three pooled plants (one from each container), were sampled in distilled water and whole root porosity was quickly measured using a pycnometer method [19, 20]. Fifty-milliliter pycnometers (one for each sample) were filled with distilled water and weighed (PW) on an analytical balance with $0.1 \mathrm{mg}$ accuracy (Mettler Toledo AG204). Roots were transferred into each pycnometer and weighed (PWR). Water excess on roots was removed by centrifugation and root fresh weight was quickly measured $(\mathrm{R})$; roots were kept in a sealed container to prevent drying. Roots were cut into approx. $1 \mathrm{~cm}$ long segments, transferred to distilled water and air was removed by a series of vacuuming (approx. 30 min total). Infiltrated root segments were then transferred back into the same pycnometers and weighed one last time (PWRi). Pycnometers and distilled water were always kept at constant temperature and handled with minimal contact to avoid temperature change. Nevertheless, water temperature was immediately measured after each weighing, using an analogue thermometer $\left( \pm 0.25^{\circ} \mathrm{C}\right.$ ) and water weight was adjusted accordingly. Porosity was calculated after water weight normalization using the formula: \%Porosity $=100 \times($ PWRi - PWR $) /$ (PW - PWR + R).

\section{Proportion of aerenchyma}

For the first experiment, eight replicates (four from each container) were sampled at 15 DPT. For the second experiment, seedlings were sampled at 7 and 14 DPT in six and nine replications (three per container) from high and low $\mathrm{P}$ conditions, respectively; one high $\mathrm{P}$ container was discarded as plants were dissimilar from the others. Root length was measured with a ruler $( \pm 0.5 \mathrm{~cm})$.

For each sample, the seminal root was sampled in Yoshida solution and $5 \mathrm{~mm}$ root segments around 20 and $30 \mathrm{~mm}$ from the root tip were cut, transferred in Yoshida solution and vacuumed for approx. $20 \mathrm{~min}$ to remove air bubbles. Segments were transferred into $5 \mathrm{ml} 3 \%$ agarose (NE-AG02 Fast Gene) at $50{ }^{\circ} \mathrm{C}$. Once solidified, blocks were sealed with plastic wrap to avoid drying and stored at $4{ }^{\circ} \mathrm{C}$ until processing (up to 9 days, no alterations observed). $75 \mu \mathrm{m}$-sections were prepared from the middle of the root segment with a vibratome (DSK Microslicer DTK-1000) and platinum coated double edge blades (Electron Microscopy Sciences). Cross sections were stained for $30 \mathrm{~s}$ in $0.0005 \%$ Toluidine blue and photographed using bright field microscopy (Olympus BX50) at $10 \times$ with an Olympus DP21 camera. For each segment, the best five pictures were manually analyzed in Image $(\mathrm{v} 1.50 \mathrm{~g})$ and root, cortex, stele and aerenchyma area were measured. Cortex zones that were damaged or adjacent to lateral roots, where aerenchyma does not develop, were excluded from measurements. Total aerenchyma area was normalized according to the percent of measured cortex. The mean of all five pictures was used for analysis.

\section{Statistical analysis}

Statistical analyses were performed in R (v3.3.0) [21, 22]. Statistical differences between the means of biological replicates were evaluated using two-way ANOVA, with genotype and treatment as factors, followed by Tukey's HSD post hoc tests. Mean differences were considered statistically significant at $p$ value $\leq 0.05$.

\section{Results}

Root porosity increased for both genotypes in low $\mathrm{P}$ (Fig. 1) and was more pronounced in DJ $(+73 \%)$ than in N4 $(+23 \%)$. In the microscopy experiments, roots were in some cases less numerous in low $\mathrm{P}$ than in high $\mathrm{P}$ at 14 and $15 \mathrm{DPT}$, but not at 7 DPT (Fig. 2). The length of all roots was very similar between treatments 


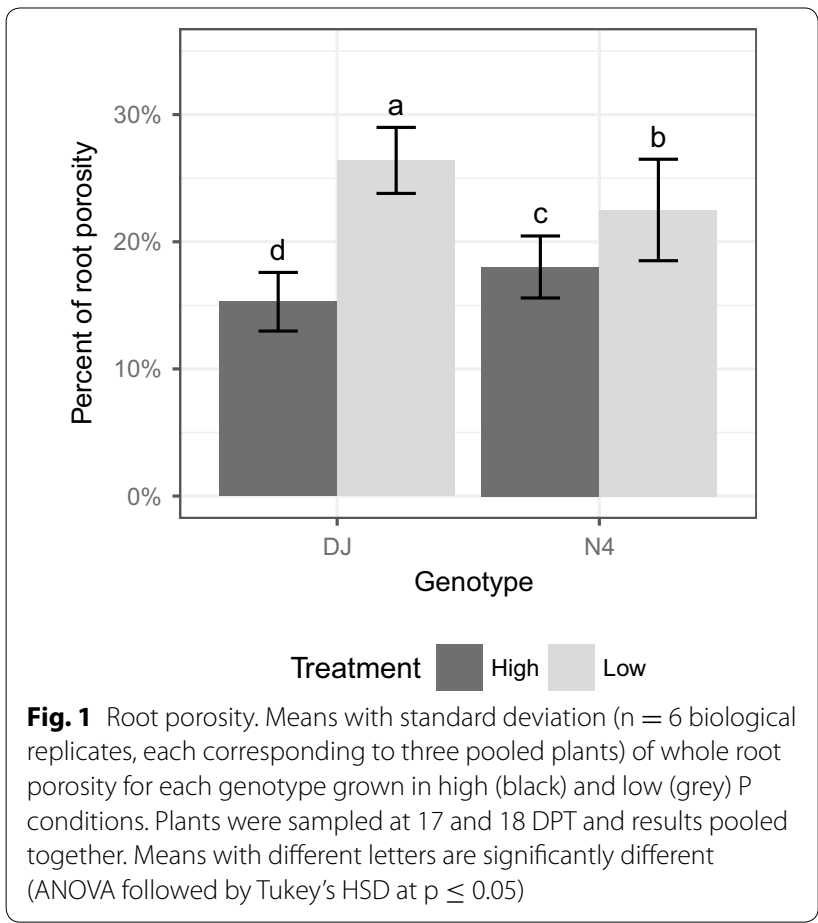

at $7 \mathrm{DPT}$, whereas at later time points, most roots were clearly longer in low $\mathrm{P}$ than in high $\mathrm{P}$ (Fig. 2). However, DJ's seminal root was not significantly longer in low $\mathrm{P}$, as opposed to N4 (Fig. 2). Interestingly, DJ's seminal root, in both treatments, did not grow much from 7 to 14 DPT, whereas for N4, it grew by $23 \%$ (two-tailed $t$ Test: $\mathrm{t}=-3.5, \mathrm{df}=10, \mathrm{p}=0.006)$ and $25 \%(\mathrm{t}=-4.8$, $\mathrm{df}=16, \mathrm{p}=0.0002)$ in high and low $\mathrm{P}$, respectively. Root diameter at 20 and $30 \mathrm{~mm}$ from DJ's seminal root tip was always similar between treatments (Additional file 1), but was wider in $\mathrm{N} 4$ in the second experiment; nevertheless, the proportion of aerenchyma in the cortex remained comparable.

Except in the first experiment at $30 \mathrm{~mm}$ from the root tip (Fig. 3A), for which results were not statistically significant, the proportion of aerenchyma in DJ was always higher in low P than in high P (Fig. 3). At $20 \mathrm{~mm}$, between 39 and $53 \%$ of the cortex was converted to aerenchyma in low P, corresponding to an increase of $45-200 \%$ in response to $\mathrm{P}$ deficiency. At $30 \mathrm{~mm}$, the proportion of aerenchyma was between 53 and $60 \%$, corresponding to an increase of $37-55 \%$. At that position $(30 \mathrm{~mm})$, most of the aerenchyma was formed; the proportion cannot reach $100 \%$ due to remaining cell walls. In N4, the proportions of aerenchyma did not vary between treatments and were similar to typical proportions seen in DJ in high P. For both genotypes in the second experiment (Fig. 3B), the proportion of aerenchyma was higher at 14 DPT than at $7 \mathrm{DPT}$, independently of the treatment or the location
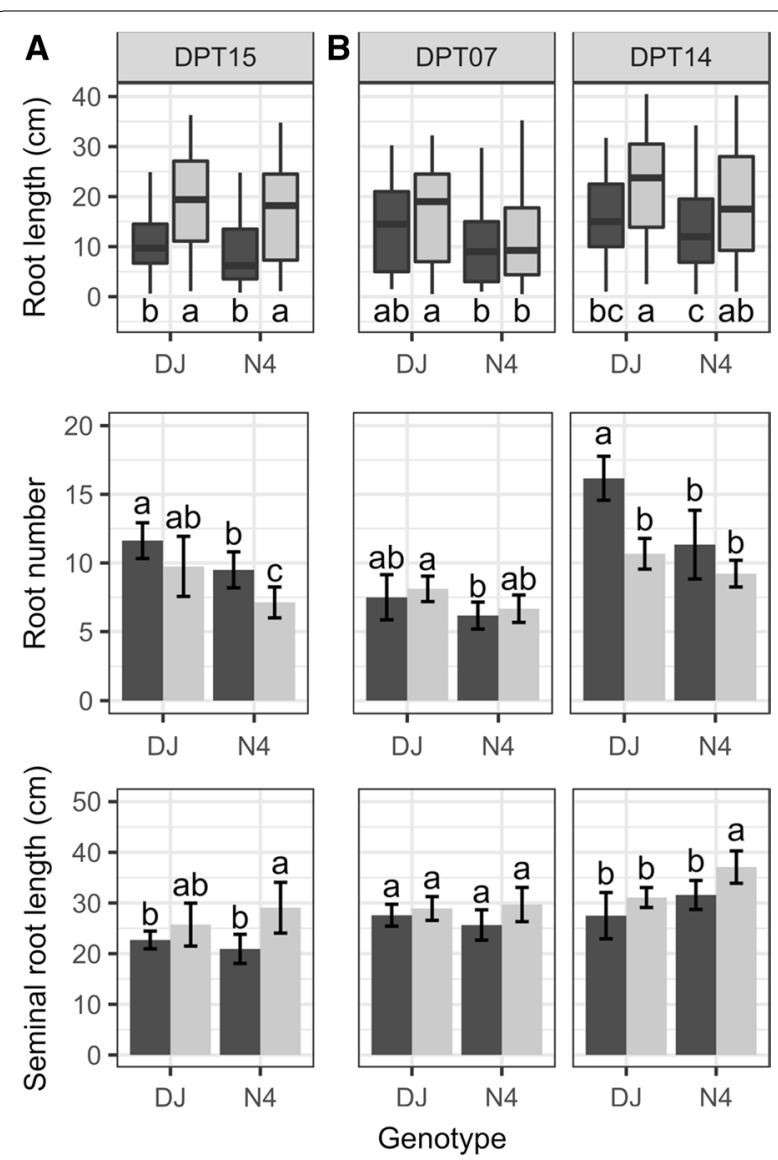

Treatment

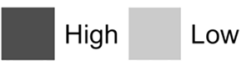

Fig. 2 Root length and number. Root length distribution of all roots and all plants (top panels) and means with standard deviation $(n=6$ to 9 biological replicates) of root number (middle panels) and seminal root length (bottom panels), for each genotype grown in high (black) and low (grey) P conditions,. The lower and upper hinge of the box show the 25th and 75th percentiles, respectively, the middle line shows the median and the whiskers show the minimum and maximum values. Plants were sampled (A) at 15 DPT (left panels) for the first experiment and (B) at 07 (middle panels) and 14 (right panels) DPT for the second experiment. Means with different letters are significantly different (ANOVA followed by Tukey's HSD at $p \leq 0.05$ )

in the root, indicating an increase in the formation of constitutive aerenchyma over time.

\section{Discussion}

Whole root porosity is known to correlate with aerenchyma formation [23]; as aerenchyma forms, porosity increases. Moreover, P deficiency is known to enhance root porosity in several species, including rice [13-15]. Here, a general increase in porosity in response to P deficiency was confirmed. Furthermore a pronounced difference in the increase of porosity between genotypes was found, with DJ displaying a far stronger response than 

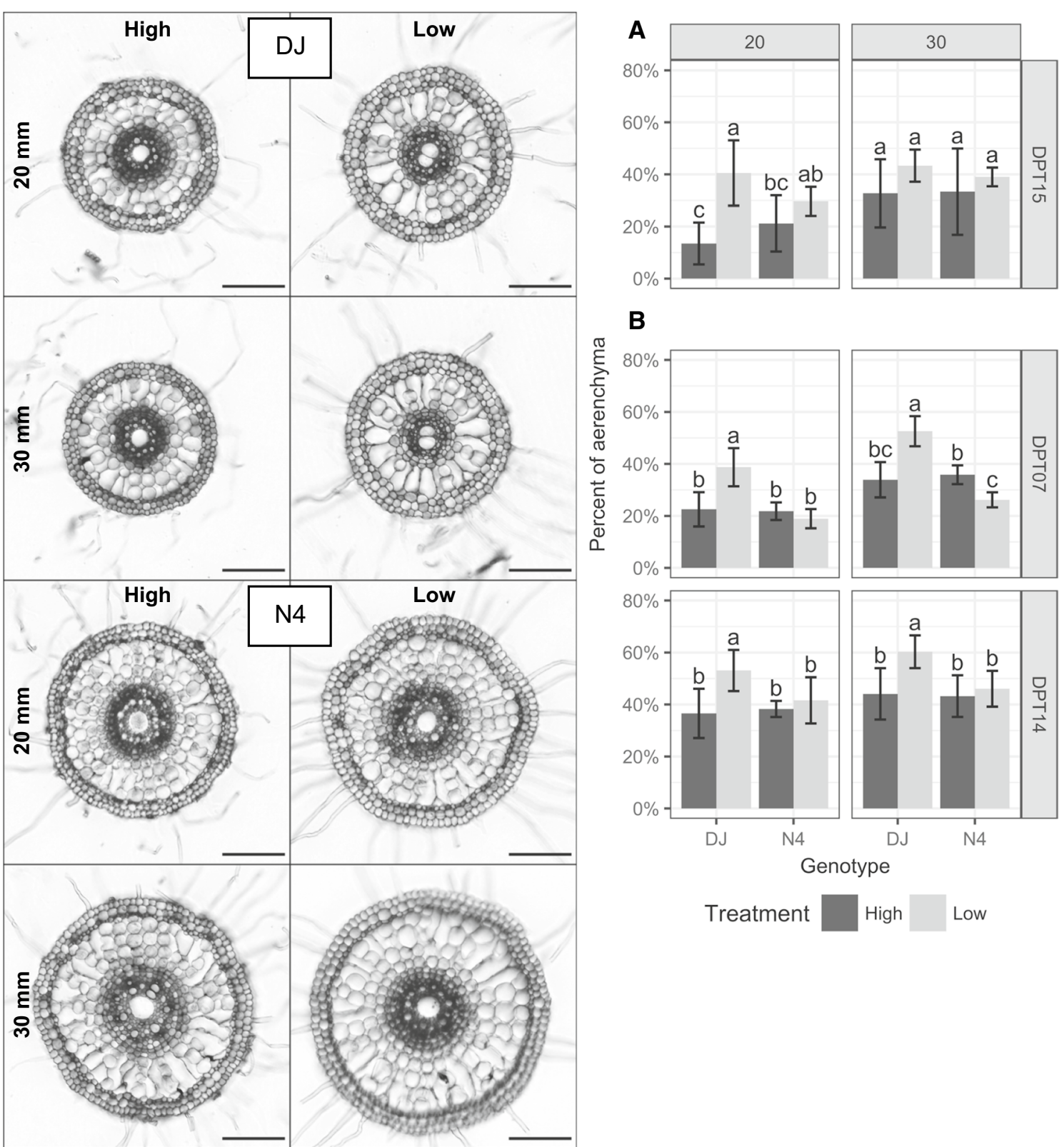

B
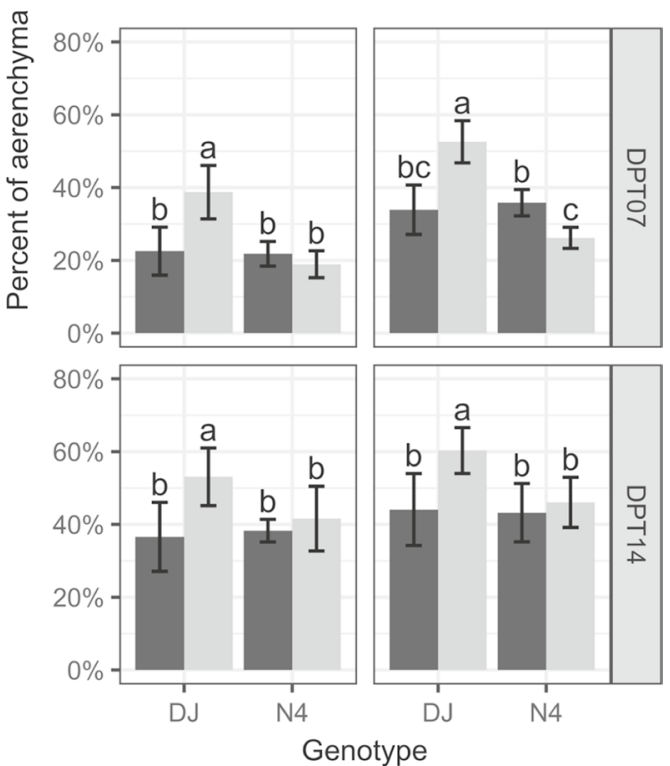

Treatment High Low

Fig. 3 Proportion of aerenchyma. Left: cross-sections at 20 and $30 \mathrm{~mm}$ from root tip of seminal root of each genotype grown in high and low $P$ conditions. Pictures were taken in bright field microscopy and correspond to the average development of aerenchyma for each genotype and each treatment at 07 DPT. Scale bars represent $100 \mu \mathrm{m}$. Right: means with standard deviation ( $n=4$ to 9 biological replicates) of the proportion of aerenchyma in seminal roots at 20 (left panels) and 30 (right panels) mm from the root tip of plants grown in high (black) and low (grey) P conditions. Plants were sampled (A) at 15 DPT for the first experiment and (B) at 07 and 14 DPT for the second experiment. Means with different letters are significantly different (ANOVA followed by Tukey's HSD at $\mathrm{p} \leq 0.05$ )

N4. These results suggest that the formation of aerenchyma was enhanced by P deficiency.

To confirm these results, the proportion of aerenchyma was directly measured in the seminal root near the tip. As aerenchyma forms constitutively in rice roots, and progresses from the apical part to the basal part [24], it is important to study it at an early stage of development. Here, 20 and $30 \mathrm{~mm}$ from the root tip were found to be optimal, as aerenchyma was sometimes barely present at $20 \mathrm{~mm}$, whereas in some cases, it was fully formed at $30 \mathrm{~mm}$. Beyond this point, the formation of constitutive aerenchyma was expected to be complete, regardless of the genotype or treatment. In addition, enhancement of inducible aerenchyma was greater at $20 \mathrm{~mm}$ than at $30 \mathrm{~mm}$, probably due to the lower proportion of constitutive aerenchyma. 
In two independent experiments, $\mathrm{P}$ deficiency enhanced the proportion of aerenchyma in DJ, demonstrating that $\mathrm{P}$ deficiency induces the formation of aerenchyma. This is in agreement with Vejchasarn et al. [12]. However, such a response was not observed for N4. It can be ruled out that these results were an artifact caused by differences in tissue age of more rapidly elongating roots under $\mathrm{P}$ deficiency, as seminal roots at $7 \mathrm{DPT}$ were similar in both treatments. The lack of enhanced aerenchyma in N4 contradicts the porosity results. However, as pointed out by Justin and Armstrong [25], root length is an important factor influencing root porosity: the longer the root, the higher the porosity (aerenchyma does not develop, or develops less in the apical part). In addition, other root structures promoted by $\mathrm{P}$ deficiency could affect root porosity. Both genotypes developed longer roots in low $\mathrm{P}$ and possibly fewer roots. Therefore, the increase in N4 porosity in response to $\mathrm{P}$ deficiency, which is much lower than that of DJ, was likely an artifact of longer roots.

Interestingly, $\mathrm{N} 4$ is sensitive to $\mathrm{P}$ deficiency while DJ is tolerant $[16,17]$. This was confirmed in the field (Additional file 2: Table S2). Although the present study does not allow a direct link, one may speculate that the inducible aerenchyma observed in DJ increases its tolerance to $\mathrm{P}$ deficiency. Aerenchyma has the potential to improve $\mathrm{P}$ utilization efficiency (PUE) by reducing cell cost maintenance and recycling nutrients $[3,4]$. In addition to utilizing P more efficiently, a genotype developing inducible aerenchyma would have the opportunity to develop additional root structures (e.g. longer roots, lateral roots and root hairs), which would then increase the volume of soil explored and thus increase $\mathrm{P}$ uptake. Interestingly, DJ has been shown to possess high internal PUE in root and shoot tissues [17] and carries a rare haplotype associated with increased PUE located on chromosome 11 [26]. DJ is also known to develop longer root hairs in $\mathrm{P}$ deficient conditions while N4 does not [27]. DJ's inducible aerenchyma could be one component leading to higher PUE and possibly to longer root hairs. Such a trait could therefore be beneficial in breeding programs to develop rice varieties with tolerance to P deficiency.

\section{Limitations}

Only two contrasting genotypes were used. More are needed to investigate the role of inducible aerenchyma in tolerance to P deficiency.

\section{Additional files}

Additional file 1. Root, cortex and stele diameter.

Additional file 2. Plant biomass in hydroponics (Table 1) and plant phenotypes in the field (Table 2).
Abbreviations

DJ: DJ123; DPT: days post-treatment; N4: Nerica4; P: phosphorus.

Authors' contributions

VP designed and performed the experiments, analyzed the data and co-wrote the manuscript. MW supervised the study and co-wrote the manuscript. Both authors read and approved the final manuscript.

\section{Acknowledgements}

Not applicable.

\section{Competing interests}

The authors declare that they have no competing interests.

\section{Availability of data and materials}

All data generated or analysed during this study are included in this published article and its additional files. Seeds can be accessed from the IRRI gene bank (IRGC117711) for DJ123 and from AfricaRice for Nerica4.

\section{Consent for publication}

Not applicable.

\section{Ethics approval and consent to participate}

Not applicable.

\section{Funding}

This work was supported by the Japan Society for the Promotion of Science (JSPS) under the "FY2014 JSPS Postdoctoral Fellowship for Foreign Researchers".

\section{Publisher's Note}

Springer Nature remains neutral with regard to jurisdictional claims in published maps and institutional affiliations.

Received: 9 November 2017 Accepted: 16 January 2018

Published online: 22 January 2018

\section{References}

1. Powers SM, Bruulsema TW, Burt TP, Chan NI, Elser JJ, Haygarth PM, et al. Long-term accumulation and transport of anthropogenic phosphorus in three river basins. Nat Geosci. 2016;9:353-6.

2. Simpson RJ, Oberson A, Culvenor RA, Ryan MH, Veneklaas EJ, Lambers H, et al. Strategies and agronomic interventions to improve the phosphorus-use efficiency of farming systems. Plant Soil. 2011;349:89-120.

3. Lynch JP. Root phenes that reduce the metabolic costs of soil exploration: opportunities for 21st century agriculture: new roots for agriculture. Plant Cell Environ. 2015;38:1775-84.

4. Postma JA, Lynch JP. Theoretical evidence for the functional benefit of root cortical aerenchyma in soils with low phosphorus availability. Ann Bot. 2011;107:829-41.

5. Yamauchi T, Shimamura S, Nakazono M, Mochizuki T. Aerenchyma formation in crop species: a review. Field Crops Res. 2013;152:8-16.

6. Hossain MA, Uddin SN. Mechanisms of waterlogging tolerance in wheat: morphological and metabolic adaptations under hypoxia or anoxia. Aust J Crop Sci. 2011;5:1094.

7. Postma JA, Lynch JP. Root cortical aerenchyma enhances the growth of maize on soils with suboptimal availability of nitrogen, phosphorus, and potassium. Plant Physiol. 2011;156:1190-201.

8. John CD. The structure of rice roots grown in aerobic and anaerobic environments. Plant Soil. 1977;47:269-74.

9. Colmer TD, Cox MCH, Voesenek LACJ. Root aeration in rice (Oryza sativa): evaluation of oxygen, carbon dioxide, and ethylene as possible regulators of root acclimatizations. New Phytol. 2006;170:767-78.

10. Joshi R, Kumar P. Lysigenous aerenchyma formation involves non-apoptotic programmed cell death in rice (Oryza sativa L.) roots. Physiol Mol Biol Plants. 2012;18:1-9. 
11. Abiko T, Obara M. Enhancement of porosity and aerenchyma formation in nitrogen-deficient rice roots. Plant Sci. 2014;215-216:76-83.

12. Vejchasarn P, Lynch JP, Brown KM. Genetic variability in phosphorus responses of rice root phenotypes. Rice. 2016;9:29.

13. Fu YQ, Yang $X J$, Shen $H$. The physiological mechanism of enhanced oxidizing capacity of rice (Oryza sativa L.) roots induced by phosphorus deficiency. Acta Physiol Plant. 2014;36:179-90.

14. Kirk GJD, Van Du L. Changes in rice root architecture, porosity, and oxygen and proton release under phosphorus deficiency. New Phytol. 1997;135:191-200.

15. Lu Y, Wassmann R, Neue HU, Huang C. Impact of phosphorus supply on root exudation, aerenchyma formation and methane emission of rice plants. Biogeochemistry. 1999;47:203-18.

16. Mori A, Fukuda T, Vejchasarn P, Nestler J, Pariasca-Tanaka J, Wissuwa M. The role of root size versus root efficiency in phosphorus acquisition in rice. J Exp Bot. 2016;67:1179-89.

17. Rose TJ, Mori A, Julia CC, Wissuwa M. Screening for internal phosphorus utilisation efficiency: comparison of genotypes at equal shoot P content is critical. Plant Soil. 2016;401:79-91.

18. Yoshida S, Forno DA, Cock JH, Gomez KA. Laboratory manual for physiological studies of rice. Los Baños: The International Rice Research Institute; 1976.

19. Jensen CR, Luxmoore RJ, VanGundy SD, Stolzy LH. Root air measurements by a pycnometer method. Agron J. 1969;61:474.
20. Van Noordwijk M, Brouwer G. Quantification of air-filled root porosity: a comparison of two methods. Plant Soil. 1988;111:255-8.

21. R Core Team. R. A language and environment for statistical computing. Vienna, Austria: R foundation for statistical computing. 2016. https:// www.R-project.org/. Accessed 1 Nov 2017.

22. RStudio Team. RStudio: integrated development for R. Boston: RStudio, Inc. 2015. http://www.rstudio.com/. Accessed 1 Nov 2017.

23. Visser EJ, Bögemann GM. Measurement of porosity in very small samples of plant tissue. Plant Soil. 2003;253:81-90.

24. Kawai M, Samarajeewa PK, Barrero RA, Nishiguchi M, Uchimiya H. Cellular dissection of the degradation pattern of cortical cell death during aerenchyma formation of rice roots. Planta. 1998;204:277-87.

25. Justin $\mathrm{S}$, Armstrong W. Evidence for the involvement of ethene in aerenchyma formation in adventitious roots of rice (Oryza sativa L.). New Phytol. 1991;118:49-62.

26. Wissuwa M, Kondo K, Fukuda T, Mori A, Rose MT, Pariasca-Tanaka J, et al. Unmasking novel loci for internal phosphorus utilization efficiency in rice germplasm through genome-wide association analysis. PLOS ONE. 2015;10:e0124215.

27. Nestler J, Wissuwa M. Superior root hair formation confers root efficiency in some, but not all, rice genotypes upon P deficiency. Front Plant Sci. 2016;7:1935.

\section{Submit your next manuscript to BioMed Central and we will help you at every step:}

- We accept pre-submission inquiries

- Our selector tool helps you to find the most relevant journal

- We provide round the clock customer support

- Convenient online submission

- Thorough peer review

- Inclusion in PubMed and all major indexing services

- Maximum visibility for your research

Submit your manuscript at www.biomedcentral.com/submit 